\title{
Dietary interventions for obesity: clinical and mechanistic findings
}

\author{
Ariana M. Chao, ${ }^{1,2}$ Kerry M. Quigley, ${ }^{2}$ and Thomas A. Wadden ${ }^{2}$ \\ 'University of Pennsylvania School of Nursing, Department of Biobehavioral Health Sciences, Philadelphia, Pennsylvania, USA. ${ }^{2}$ Department of Psychiatry, Perelman School of Medicine at the University of \\ Pennsylvania, Philadelphia, Pennsylvania, USA.
}

\begin{abstract}
Dietary modification is central to obesity treatment. Weight loss diets are available that include various permutations of energy restriction, macronutrients, foods, and dietary intake patterns. Caloric restriction is the common pathway for weight reduction, but different diets may induce weight loss by varied additional mechanisms, including by facilitating dietary adherence. This narrative Review of meta-analyses and select clinical trials found that lower-calorie diets, compared with higher-calorie regimens, reliably induced larger short-term ( $<6$ months) weight losses, with deterioration of this benefit over the long term (>12 months). Few significant long-term differences in weight loss were observed for diets of varying macronutrient composition, although some regimens were found to have short-term advantages (e.g., low carbohydrate versus low fat). Progress in improving dietary adherence, which is critical to both short- and long-term weight loss, could result from greater efforts to identify behavioral and metabolic phenotypes among dieters.
\end{abstract}

\section{Introduction}

Dietary modification is a cornerstone of weight control. At a fundamental level, weight loss requires achieving a state of negative energy balance. The best way to attain this balance is a subject of much debate and ultimately relies on finding a strategy that people can follow in the long term. People seeking weight loss have a variety of methods to choose from, including calorie restriction with different macronutrient composition; avoidance (or consumption) of specific foods; and dietary patterns. Dietary approaches may work on distinct mechanisms related to weight control, and features of diets can make adherence more or less difficult. Knowledge of these mechanisms could help to optimize and tailor dietary approaches for obesity treatment.

In this narrative Review, we highlight well-known dietary approaches for obesity treatment in adults and potential mechanisms contributing to weight loss, emphasizing mechanisms that influence adherence. These topics are reviewed using meta-analyses and selected research studies. We address the following questions: (a) Among adults with overweight/obesity, what are the short-term ( $<12$ months) and longer-term ( $\geq 12$ months) weight losses with different degrees of prescribed energy restriction? (b) Does the timing (e.g., intermittent fasting), macronutrient composition (e.g., low carbohydrate versus low fat), or dietary pattern (e.g., Mediterranean) affect the amount of weight loss on a shortor long-term basis? (c) What physiological and behavioral mechanisms are associated with specific types of dietary interventions that may contribute to dietary adherence and weight loss?

Conflict of interest: AMC reports grants and consulting fees from WW International Inc., outside the submitted work. TAW discloses serving on advisory boards for Novo Nordisk and WW International Inc.

Copyright: (c) 2021, American Society for Clinical Investigation.

Reference information: J Clin Invest. 2021;131(1):e140065.

https://doi.org/10.1172/JCl140065.

\section{Dietary adherence}

Substantial variability in weight loss is observed with all dietary interventions, some of which is likely attributable to participants' varying degrees of adherence. In persons with obesity, self-reports of adherence to calorie prescriptions typically underestimate energy intake by $30 \%$ to $50 \%$ as compared with measurement by doubly labeled water $(1,2)$. Given the expense of doubly labeled water and lack of accurate dietary biomarkers (3), investigators typically rely on participants' self-reported food and calorie intake. Newer approaches include calculating changes in energy intake with mathematical modeling and measurements of body weight $(4,5)$. Reduction in self-reported calories consumed is often used to quantify adherence to an energy-reduced diet. Diet adherence scores calculated from self-reported food intake can assess how closely patients followed a particular dietary pattern. Even with the inaccuracies of these methods, closer self-reported dietary adherence is associated with greater weight loss and less weight regain (6-10).

Figure 1 presents a conceptual framework of physiological, psychological, behavioral, and sociocultural/environmental mechanisms that may influence dietary adherence and subsequent weight loss. Adherence is influenced by the components of the prescribed diet and processes that precipitate eating (initiation), end an eating episode (satiation), and inhibit appetite between meals (satiety). The model builds upon the Satiety Cascade Framework by Blundell and others (11-14), modifications by Mela (15), and relevant behavioral adherence schemata (16). The Satiety Cascade posits that food choice, satiation, and satiety are influenced by sensory (e.g., recognition), cognitive (e.g., prior beliefs and associations, anticipated reward and pleasure), postingestive (e.g., texture, gastric stretch, and appetite-related hormones), and postabsorptive signals (e.g., insulin). We refer to aspects of this framework in reviewing the mechanisms associat- 


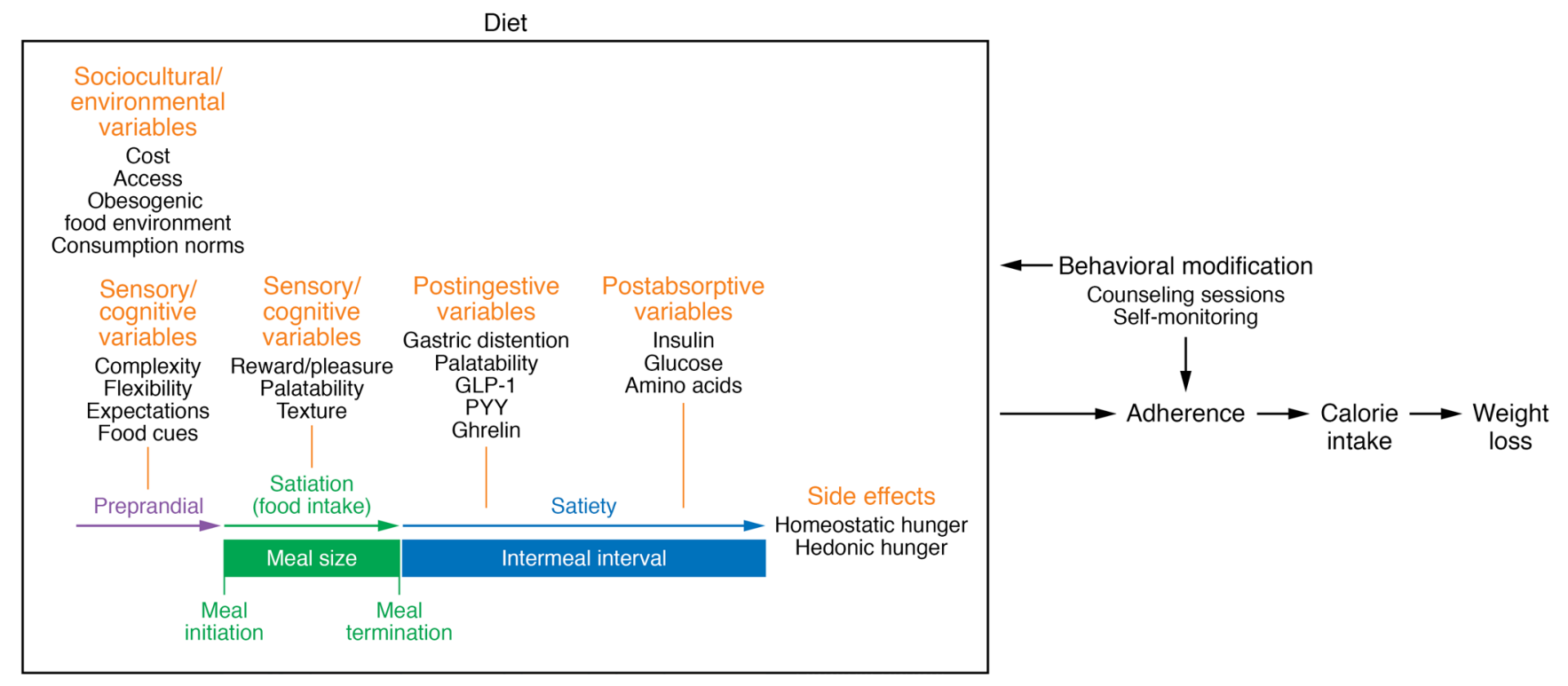

Figure 1. Conceptual model of mechanisms associated with different diets that can improve adherence and subsequent weight loss. The orange headings highlight variables associated with various diets that may influence individual adherence. Adapted from Blundell and others (11-14) and Mela (15) with permission.

ed with dietary approaches below. All diets should be prescribed with lifestyle modification to facilitate adherence (17), including recording of food and calorie intake using applications or paper diaries (18-22).

\section{Energy-restricted diets}

Energy balance relies on an interplay between energy intake and expenditure. Dietary energy can be derived from protein, carbohydrate, fat, and ethanol. Total energy expenditure is the sum of resting metabolic rate, thermic effect of food, and physical activity-related energy expenditure (including non-exercise activity thermogenesis) (23). To lose weight, "energy in" (i.e., dietary energy intake) must be less than "energy out" (i.e., total energy expenditure). Thus, most dietary interventions for weight loss prescribe some form of energy restriction.

\section{Balanced-nutrient, low-energy diets}

Low-energy diets (LEDs) are generally defined by energy intake targets of $800-1800 \mathrm{kcal} / \mathrm{d}$, prescribed with higher calories for heavier individuals. A common prescription is $1200-1500 \mathrm{kcal} / \mathrm{d}$ for individuals who weigh less than $113.6 \mathrm{~kg}$ and $1500-1800 \mathrm{kcal} / \mathrm{d}$ for those who weigh at least $113.6 \mathrm{~kg}$. Alternatively, an energy deficit of 500-750 kcal/d may be prescribed, based on energy expenditure estimations $(24,25)$. LEDs prescribe a balanced profile of nutrients, similar to recommendations for the general population (i.e., $45 \%-65 \%$ carbohydrate, $20 \%-35 \%$ fat $[\leq 10 \%$ from saturated fat], and $10 \%-35 \%$ protein) $(26,27)$.

\section{Very low-energy diets}

VLEDs prescribe less than $800 \mathrm{kcal} / \mathrm{d}$ while aiming to provide essential nutrients. They are delivered as meal-replacement shakes or protein-sparing modified fasts consisting of lean meat, fish, and fowl supplemented with a multivitamin and 2-3 g/d of potassium. Both approaches provide approximately 70-100 g/d of protein, designed to spare the loss of lean body mass (28-30). The 2013 AHA/ACC/TOS Guideline for the Management of Overweight and Obesity in Adults suggested that VLEDs be prescribed in limited cases, such as in preparation for bariatric surgery (24). VLEDs should only be used as part of a comprehensive lifestyle intervention with appropriate medical supervision owing to rapid weight losses and potential for side effects (e.g., cholelithiasis, dehydration) $(24,31)$. Strict adherence to these regimens is only possible for limited durations because energy content is at or below resting metabolic rate. When patients reach their desired weight loss goals, calorie intake should be gradually increased to a level consistent with their new, lower body weight (e.g., increasing calories by $100 \mathrm{kcal} /$ wk until weight stabilizes).

\section{Weight loss}

Greater caloric restriction, with its larger resulting negative energy deficit, is associated with a faster rate of weight reduction in the short term (32). A meta-analysis included six randomized controlled trials (RCTs) that compared low-fat LEDs with VLEDs, in which each approach was combined with lifestyle modification and had a follow-up of at least 1 year (28). LEDs prescribed for an average of 12.7 weeks induced a mean loss of $9.7 \%$ of initial weight, compared with $16.1 \%$ for VLEDs (Table 1 ). At $>1$ year, mean weight loss with LEDs had declined to $5.0 \%$, which was similar to the $6.3 \%$ observed with VLEDs. Participant attrition was $22.6 \%$ with LEDs and $22.3 \%$ with VLEDs over a mean follow-up of 29 months. In another review of RCTs, participants randomized to LEDs lost $6.4 \mathrm{~kg}$ at 1 year, compared with $10.3 \mathrm{~kg}$ for those treated with VLEDs (for a median length of 10 weeks), both as combined with lifestyle modification (33). Six of these studies included data at 2 years, at which time participants originally assigned to LEDs had lost $2.8 \mathrm{~kg}$, compared with $4.2 \mathrm{~kg}$ for those assigned to 


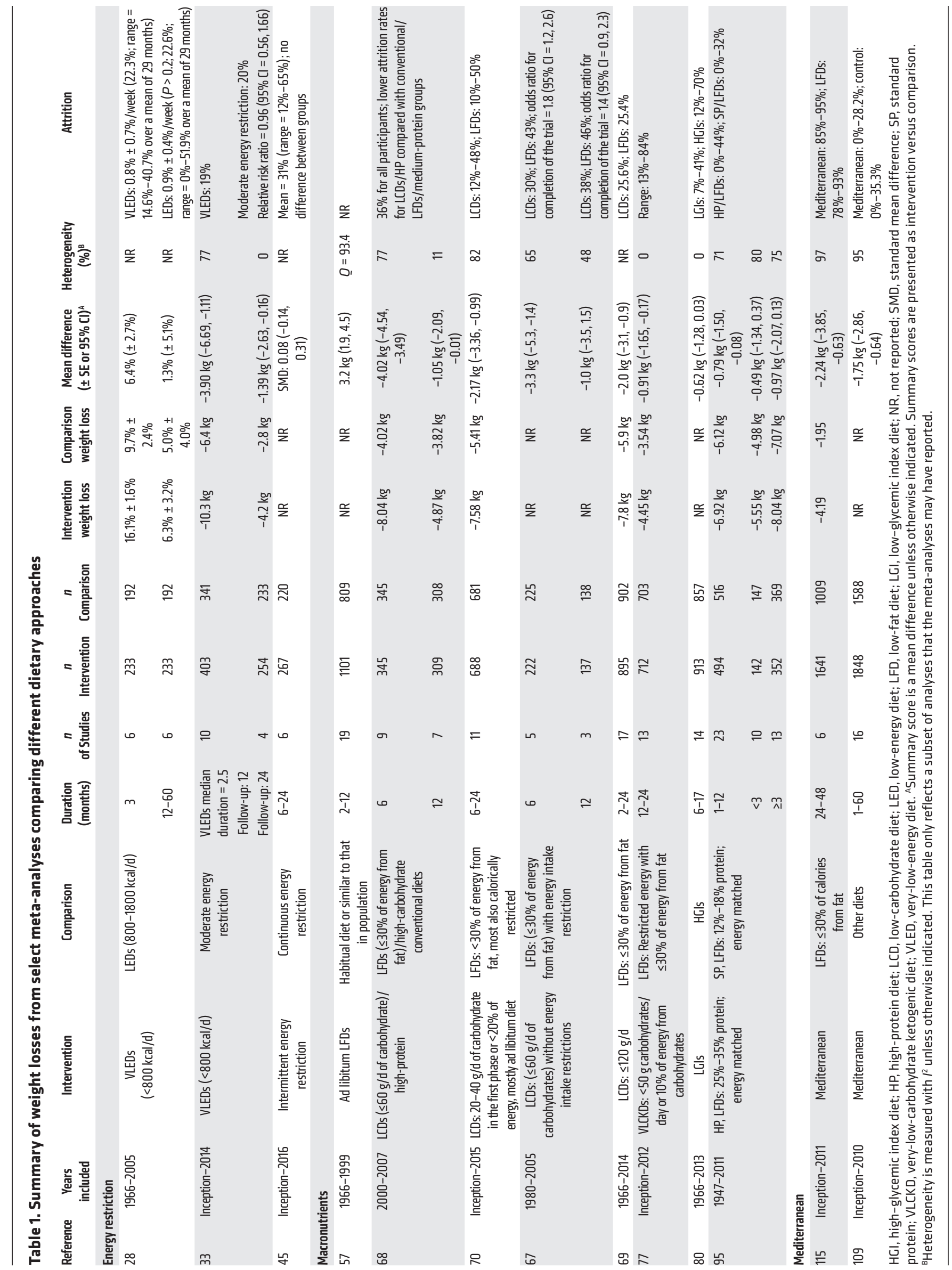


VLEDs. Participants were as likely to discontinue VLEDs as they were LEDs (risk ratio $=0.96 ; 95 \%$ confidence interval $[\mathrm{CI}]=0.56$, 1.66). Results of the systematic review from the 2013 AHA/ACC/ TOS Guideline for the Management of Overweight and Obesity in Adults showed that LEDs, when combined with lifestyle modification, induced mean weight losses of 5-8 kg in 6 months, which were maintained at 1 year with continued lifestyle counseling (24). The review further found that VLEDs produced as much as twice the short-term weight loss produced by LEDs, but differences between the approaches declined over time.

\section{Portion-controlled diets}

One way to improve simplicity and adherence is to use portion-controlled servings of conventional foods or liquid meal replacements (and meal bars) that provide foods of predetermined quantity and calories. Prescribed diets of $1000-1500 \mathrm{kcal} / \mathrm{d}$ using portion-controlled foods increased initial weight losses by $2.5-3.0 \mathrm{~kg}$ at 3-6 months, as compared with the prescription of a self-selected diet of conventional foods with the same calorie goal (34-37). Portion-controlled meals, as compared with self-selected diets, continue to produce larger weight losses at 12-18 months, although both approaches are associated with gradual weight regain (34).

\section{Mechanisms}

In the studies reviewed, greater energy deficits induced with VLEDs were sufficient to produce greater mean short-term weight losses than LEDs. Portion-controlled diets appear to improve dietary adherence by reducing participants' tendency to underestimate calorie intake $(2,38)$. The use of meal replacements, in particular, reduces complexity related to planning and preparing foods, decreases cognitive demands and decision making, and reduces cues for overeating (39). Meal replacements may support adherence to calorie goals through sensory-specific satiety (40).

\section{Importance of initial weight loss}

Meal replacements have been used increasingly in RCTs to boost initial weight losses. Observational data from the Look AHEAD study, which provided meal replacements for the first 4 months of treatment, found that individuals who lost the most weight in the first 1-2 months had the largest weight losses at 1 year and were the most likely to achieve a loss of $10 \%$ or more of initial weight at this time (41). In a post hoc analysis of the study, 1-year losses of greater than $10 \%$ (achieved by $37 \%$ of Look AHEAD participants) were associated with significant reductions in all-cause mortality, as compared with a usual-care group, over a median follow-up of 10.2 years (42). The DiRECT trial compared best-practice routine care with an integrated weight-management intervention that included a total meal replacement diet of $825-853 \mathrm{kcal} / \mathrm{d}$ for 12-20 weeks. The latter approach was associated with greater odds of achieving a loss of at least $15 \mathrm{~kg}$ and diabetes remission at 1 and 2 years $(43,44)$. Taken together, these findings suggest that patients with type 2 diabetes and obesity should be prescribed meal replacements more frequently than LEDs of conventional foods to help them lose weight (43). VLEDs, with their large 1-year weight losses, could be valuable in producing greater long-term improvements in health than LEDs, despite the modest differences in long-term weight loss produced by these two approaches.
A randomized trial would be needed to address this question, as would a cost analysis, as 6 months of participation in a medically supervised program with VLEDs supplied as meal replacements can easily exceed $\$ 3000$.

\section{Intermittent energy restriction}

Intermittent energy restriction instructs dieters to alternate between fasting and unrestricted eating periods and includes intermittent fasting and time-restricted feeding. Intermittent fasting consists of "fast days" of $\geq 60 \%$ energy restriction on 2-3 days per week - e.g., on alternate days (ADF), or 2 non-consecutive days (5:2 diet) - and "fed days," with a specified dietary composition or ad libitum consumption at or above daily energy needs. Time-restricted feeding may take the form of eating for 8 hours and then fasting for the remaining 16 hours of the day. Adherence is often measured as the difference between self-reported energy intake and prescribed energy intake on fast and fed days.

\section{Weight loss}

Intermittent fasting and daily energy restriction result in similar short- and long-term weight loss, when isocaloric intakes are prescribed. A meta-analysis of 6 studies examining the effects of intermittent versus continuous isocaloric energy restriction over 6 months observed similar weight losses between interventions (standard mean difference [SMD] = 0.08; Table 1 and ref. 45). Participant attrition at $\geq 6$ months was variable across studies but similar between the intermittent and continuous energy restriction groups. In one of the largest studies $(n=100)$ comparing ADF with daily energy restriction, those in ADF lost $6.0 \%$ of baseline weight at 1 year, which did not differ significantly from $5.3 \%$ observed in the daily (isocaloric) restriction group (46). A higher proportion of participants in the latter group reported adhering to their dietary goals. Participants in ADF reported eating more than their prescribed energy goal on fast days and less than their goal on feast days.

\section{Mechanisms}

Several factors could make intermittent fasting a potentially useful dietary approach from an adherence perspective, although there are not yet adequate data on this topic. Intermittent fasting may address the challenges of behavioral fatigue and dietary monotony that some individuals report with continuous energy restriction (47). Intermittent restriction only requires individuals to limit their intake for defined days, which may be easier for some to adhere to than continuous energy restriction. Further research is needed to determine whether intermittent energy restriction is particularly helpful with subsets of individuals who report that the monotony or daily demands of continuous energy restriction undermine their dietary adherence and, thus, ultimate weight loss. Moreover, long-term adherence to intermittent versus continuous energy restriction should be assessed to determine whether the former approach might be superior to the latter in facilitating weight loss maintenance, as compared with weight loss induction. Compared with continuous energy restriction, $\mathrm{ADF}$ and 5:2 intermittent fasting diets do not significantly increase hunger, fullness, desire to eat, or food preoccupation after 3-4 months $(48,49)$. However, at 1 year, greater hunger levels were reported with 5:2 intermittent fasting than with continuous energy restriction (50). A limited 
number of controlled trials have addressed the effects of intermittent fasting on appetite; the majority examined ADF or 5:2 diets, and many studies had small samples. Investigators have hypothesized that intermittent energy restriction improves resting energy expenditure and metabolic flexibility, though these physiological benefits for weight management are unclear (51).

\section{Macronutrient-focused diets}

Finding the optimal macronutrient ratio to promote weight loss has received substantial attention. Diets with different macronutrient compositions may be prescribed using caloric restriction or ad libitum without a specific calorie goal (under the theory that lower calorie intake will be achieved by restriction or elimination of particular foods). The most common macronutrient manipulations are low fat, low carbohydrate, and high protein. There are no standard definitions of low versus high amounts of macronutrients, and many variations have been used. Inability to vary macronutrients independently of one another has largely clouded interpretation of these studies. Adherence is commonly based on the agreement between the primary macronutrient goal(s) of the assigned diet and participants' reported intake.

\section{Low-fat diets}

Low-fat diets (LFDs) are a standard weight loss strategy and generally prescribe less than $30 \%$ of calories from fat. They may be implemented by providing specific menus emphasizing low-fat foods, or having patients count fat grams rather than calories. Most LFDs used for obesity treatment include calorie restriction $(52,53)$.

Weight loss. LFDs, which are typically similar to the diets described in the comparison of LEDs and VLEDs, are among the best-studied approaches to weight loss. Several large, multicenter, randomized trials - Diabetes Prevention Program (DPP) and Look AHEAD - have demonstrated the efficacy of LFDs for losing weight and improving comorbid conditions as compared with usual care. DPP examined 3234 participants with overweight/ obesity and impaired glucose tolerance randomly assigned to placebo, metformin (850 mg twice daily), or a lifestyle intervention designed to induce a $7 \%$ loss of initial weight (54). The lifestyle intervention instructed participants to reduce fat intake to less than $25 \%$ of daily calories and limit food intake to $1200-2000$ $\mathrm{kcal} / \mathrm{d}$ depending on initial weight (53). At 1 year, the lifestyle group lost $7.1 \mathrm{~kg}$, compared with losses of $2.8 \mathrm{~kg}$ in the placebo group and virtually no weight change in the placebo group (55). At 1 year, the median, self-reported percentage fat intake was $27.1 \%$ in the lifestyle group (56). Average duration of treatment was 2.8 years, at which time lifestyle participants lost $5.6 \mathrm{~kg}$, compared with losses of $2.1 \mathrm{~kg}$ and $0.1 \mathrm{~kg}$ in the metformin and placebo groups, respectively (54).

LFDs also have been prescribed without caloric restriction, allowing patients ad libitum consumption of select carbohydrates, while avoiding high-fat foods. Investigators have hypothesized that such diets, with the greater volume of food intake allowed, would increase satiety (while reducing hunger) and induce gradual weight loss. However, the weight loss efficacy of such diets is uncertain. One meta-analysis of trials 2 months or longer examined ad libitum LFDs compared with control diets in which partic- ipants were advised to maintain their regular diet (or to consume a diet with a fat content similar to that consumed by the community population) (Table 1 and ref. 57). Low-fat interventions had a mean, self-reported dietary fat reduction of $10.8 \%$ of energy. Compared with the control groups, the low-fat interventions produced a $272 \mathrm{kcal} / \mathrm{d}$ greater energy decrease and $3.2 \mathrm{~kg}$ greater weight loss. However, this meta-analysis included people across the weight spectrum. Few long-term, controlled trials have examined this question in patients with obesity.

Mechanisms. Several mechanisms could contribute to weight loss with LFDs (58). Some of these pertain to limiting fat itself, whereas others are a consequence of the increased proportion of carbohydrate and protein that occur with fat restriction. Fat lends flavor and palatability to foods and provides the "mouthfeel" that makes them hedonically rewarding. Fat has $9 \mathrm{kcal} / \mathrm{g}$, compared with carbohydrates and proteins, which have $4 \mathrm{kcal} / \mathrm{g}$. Fat is less satiating than carbohydrates or proteins, mostly because of its higher energy density and palatability (59-61). Fullness and satiation increase with the volume of food ingested. Thus, compared with high-protein or high-carbohydrate foods, isocaloric amounts of high-fat foods, by virtue of their smaller physical volume, will be less likely to trigger satiation signals such as gastric distention (62-64). These properties predispose people to overeat high-fat foods $(15,65)$. Decreasing fat typically allows patients to eat a greater volume of food, which facilitates satiation and decreases overall energy intake.

\section{Low-carbohydrate diets}

Low-carbohydrate diets (LCDs) emphasize restriction of carbohydrate and replacement with fat and/or protein. LCDs prescribe $60-130 \mathrm{~g}$ of carbohydrate per day $(\leq 20 \%-45 \%$ of daily energy intake). Very-low-carbohydrate regimens recommend less than $60 \mathrm{~g}$ of carbohydrate per day.

Weight loss. LCDs generally produce greater short-term $(<6$ months) weight losses than LFDs, with roughly equivalent longterm (>12 months) weight losses between approaches. At least 10 meta-analyses have evaluated the effectiveness of these regimens for losing weight and improving metabolic parameters (66). Compared with LFDs, LCDs produced 3.3-4.0 kg greater weight loss at 6 months $(67,68)$. However, at 12-24 months, differences between these approaches declined to only 2-2.2 $\mathrm{kg}$ in favor of low-carbohydrate regimens (Table 1 and refs. 66, $69,70)$. For example, at 6 months, participants assigned to a low-carbohydrate, high-protein, high-fat diet lost $7.0 \%$ of body weight, which was significantly more than the $3.2 \%$ produced by a low-calorie, high-carbohydrate, low-fat regimen. However, at 12 months, differences between groups were no longer significant ( -4.4 vs. $-2.5 \%$ of initial body weight, respectively) (71). In the DIETFITS trial, participants were randomized to a healthy LFD or LCD. Intake of total fat or digestible carbohydrates was prescribed as $20 \mathrm{~g} / \mathrm{d}$ during the first 8 weeks, and participants gradually increased fat or carbohydrate intake until they reached the lowest level they believed they could maintain indefinitely. Weight loss did not differ between groups at 12 months (72). A meta-analysis of 19 trials further demonstrated that short- and long-term weight losses were similar with LCDs and LFDs when isocaloric regimens were prescribed (73). 
Very-low-carbohydrate ketogenic diets. Very-low-carbohydrate ketogenic diets (VLCKDs) are one of the most popular forms of LCD and are designed to induce ketosis. They restrict carbohydrate to less than $20 \mathrm{~g} / \mathrm{d}$ during phase 1 , which usually lasts up to 12 weeks, and then gradually increase it to $80-100 \mathrm{~g} / \mathrm{d}$. The amount of carbohydrate restriction needed to achieve ketosis varies by person but is typically less than $50 \mathrm{~g} / \mathrm{d}$ (74). Such diets usually provide $70 \%-80 \%$ fat, since eating too much protein can prevent ketosis (because amino acids can be converted to glucose via gluconeogenesis) (75).

A meta-analysis of six studies of VLCKDs, which lasted less than 4 weeks, revealed a mean weight loss of $10.0 \mathrm{~kg}$ (Table 1 and ref. 76). A different set of six studies lasted $\geq 4$ weeks and reported an average weight loss of $15.6 \mathrm{~kg}$. In a meta-analysis of studies lasting $\geq 12$ months, VLCKDs resulted in modestly greater weight loss than energy-restricted diets, with less than $30 \%$ of calories from fat (weighted mean difference $=-0.91 \mathrm{~kg}$ ) $(77)$. However, adherence to the carbohydrate prescription, as assessed by 3-day dietary recalls, was low $(7,77)$. For example, participants in the first phase of one VLCKD consumed $35 \mathrm{~g} / \mathrm{d}$ more carbohydrate than prescribed and, at 1 year, ate $86 \mathrm{~g} / \mathrm{d}$ more than prescribed (7).

Low-glycemic index diets. Low-glycemic index diets (LGIs) represent another low-carbohydrate approach. Carbohydrate quantity and type (e.g., whole grain versus refined grain) have differential effects on postprandial glucose (78). This is of uncertain benefit. Compared with isocaloric control diets, LGIs produced similar weight losses (SMD $=-0.10 ; 95 \% \mathrm{CI}=-0.22$, 0.01) (79). High- and low-glycemic diets resulted in similar weight loss at $\geq 6$ months (Table 1 and ref. 80). However, LGIs generally had more favorable effects on glucose (81).

Mechanisms. Many arguments that favor decreasing carbohydrate pertain to the effects of high-glycemic foods, including refined starches and sugar (82). According to the carbohydrate-insulin model, diets high in carbohydrate increase postprandial glucose and insulin secretion and direct metabolic fuels away from oxidation and toward storage in adipose tissue, decreasing energy expenditure and increasing hunger (82-84). Evidence supporting the model is mixed (85). Some studies show that LCDs are associated with suppression of appetite-stimulating hormones such as insulin and ghrelin (86). Postprandial secretion of the satiety hormones GLP-1 and PYY also tends to increase more with low-carbohydrate/high-fat meals than with isocaloric low-fat/ high-carbohydrate meals $(87,88)$. However, one study found that compared with a ketogenic LCD, a plant-based LFD with a higher glycemic load and postprandial glucose and insulin response resulted in less energy intake and no significant differences in hunger (89). Low-carbohydrate foods may also reduce caloric intake by decreasing cravings and preference for high-carbohydrate and high-sugar foods (90).

Additional mechanisms related to ketosis arise with severe carbohydrate restriction. At 12 weeks, VLCKDs are associated with reduced hunger and desire to eat, though there are minimal effects on satiety $(91,92)$. Appetite-suppressing effects may be due to ketosis or other properties of VLCKDs, including increased protein or fat intake $(91,92)$. About $500 \mathrm{~g}$ of glycogen are stored in the liver and muscle, and each gram of glycogen is associated with approximately $3 \mathrm{~g}$ of water. VLCKDs deplete glycogen stores, and the accompanying diuresis explains some of the greater short-term weight losses with LCDs (93). Sustaining carbohydrate restriction sufficient to maintain ketosis is challenging. Few people have detectable urinary ketones after 3-6 months on VLCKDs, likely owing to imperfect adherence $(71,94)$.

\section{High-protein diets}

High-protein diets prescribe $\geq 25 \%$ of calories from protein or $\geq 1.6$ $\mathrm{g}$ of protein per kg of body weight. Higher protein content is a feature of many lower-fat and lower-carbohydrate diets.

Weight loss. There is mixed evidence that high- versus low-protein diets result in differential weight losses. A meta-analysis of 24 trials comparing the short-term effects (mean trial duration of 12 weeks) of energy-restricted, isocaloric high-protein/low-fat versus standard-protein/low-fat diets found modest differences in weight between groups $(-0.79 \mathrm{~kg}$; $95 \% \mathrm{CI}=-1.50,-0.08$; Table 1 and ref. 95). A meta-analysis of 15 trials comparing the longer-term $(\geq 12$ months) effects of LFDs combined with either high or low protein intake revealed no differences in weight loss between diets $(-0.39$ $\mathrm{kg}$; 95\% CI $=-1.43,0.65)$ (96). The DIOGENES trial examined ad libitum, high- versus low-protein diets. After an initial 8-week LCD, compared with low-protein diets, participants randomized to high-protein diets regained $0.93 \mathrm{~kg}$ less and $2.8 \mathrm{~kg}$ less weight at 26 weeks and 1 year, respectively $(97,98)$. In another study testing the use of high protein for weight loss maintenance, weight loss did not differ among participants randomized to high-protein or high-carbohydrate diet at 64 weeks. However, participants who reported higher protein intake had greater weight loss than those with lower protein consumption (99).

Mechanisms. Proponents of higher protein intake note that protein is more satiating than carbohydrate or fat under most conditions $(100,101)$, which may result in weight loss through reduced caloric intake (102). These may be modest effects that fall short of producing additional clinically significant weight loss, as described above. Independent of its possible effects on appetite, higher protein intake spares the loss of fat-free mass during weight loss, particularly in older adults $(103,104)$. A high-protein diet compared with a moderate-protein diet may also create a negative energy balance that counteracts adaptive thermogenesis during weight loss maintenance (105).

\section{Comparison of multiple macronutrient manipulations}

Several trials have compared three or more macronutrient permutations or diet types. The POUNDS Lost study randomized participants to calorie-restricted diets low or high in fat (20\% or $40 \%)$ with normal or high protein (15\% or $25 \%)$. Carbohydrate content ranged from $35 \%$ to $65 \%$ of calories (106). Weight losses did not differ among participants and were 6-7 kg after 6 months and 5 $\mathrm{kg}$ at 2 years. Across diets, mean reported energy intake and target levels for macronutrients did not reach prescribed levels at 6 months or 2 years. Cravings, fullness, hunger, and diet satisfaction were similar across diets. Another study compared participants randomly assigned to the Atkins, Zone (macronutrient balance of $40 \%$ carbohydrate, $30 \%$ fat, and 30\% protein), Weight Watchers (calorie restriction), or Ornish diets ( $<10 \%$ of calories from fat) and found no significant difference in weight loss at 1 year (6). 
Only level of adherence to the prescribed diet was associated with weight loss. Taken together, these findings show that macronutrient composition has little effect on long-term weight loss, even with efforts to hold the level of caloric restriction constant.

\section{Dietary patterns}

Many scientists and consumers have shifted their attention to dietary patterns rather than focusing on specific foods or food types (107). Several types of dietary patterns, as exemplified by the Mediterranean diet, have evolved that place a greater concern on health than on weight loss per se. This approach tends to emphasize the quality and nature of macronutrients more than quantity. Dietary patterns examined to date generally produce modest weight loss, unless they are combined with energy restriction $(108,109)$.

\section{Mediterranean diet}

The term "Mediterranean diet" refers to a dietary pattern common in olive-growing areas of the Mediterranean region. This diet includes high consumption of vegetables, fruits, legumes, and grains; moderate consumption of red wine and dairy products; and relatively low intake of meat and meat products $(110,111)$. There is no consensus on the exact definition of a Mediterranean diet. Mediterranean diets not prescribed for weight loss recommend approximately $2226 \mathrm{kcal} / \mathrm{d}$ with $36.6 \%$ of daily intake from fat, including $18.8 \%$ as monounsaturated fat and $4.8 \%$ as polyunsaturated fat (112). Several tools have been developed to measure adherence to Mediterranean diets that are based on composite measures of self-reported food, food groups, nutrients, and/or ratios of nutrients $(113,114)$.

Weight loss. A meta-analysis of 16 RCTs of Mediterranean diets versus other diets (e.g., low-fat, high-carbohydrate; Table 1) suggested that the former diet reduced weight and metabolic abnormalities when total energy intake was restricted or when combined with increased physical activity (109). Mediterranean diets reduced weight more than control diets by a mean of $1.8 \mathrm{~kg}$ $(95 \% \mathrm{CI}=0.6,2.9)$ over a duration of $1-60$ months. Larger reductions in weight were observed when the diets were also energy restricted $(-3.9 \mathrm{~kg} ; 95 \% \mathrm{CI}=-6.5,-1.2)(109)$. A meta-analysis of six trials that compared Mediterranean with low-fat diets $(\leq 30 \%$ of total energy as fat) found that at 2 years of follow-up, the Mediterranean diet produced greater reductions in weight $(-2.2 \mathrm{~kg})$ (115). The DIRECT trial showed stronger effects on weight loss of a calorically restricted, Mediterranean diet $(-4.4 \mathrm{~kg})$ and of a low-carbohydrate, non-calorically restricted diet $(-4.7 \mathrm{~kg})$ compared with a calorically restricted LFD $(-2.9 \mathrm{~kg})$ at 2 years $(116)$. Across diets, self-reported adherence was $81 \%$ in the first month of the intervention and dropped to $57 \%$ at 24 months, with no significant differences among groups (117). In the ongoing PREDIMED-Plus intensive lifestyle intervention study, nearly 7000 participants were randomized to an energy-restricted Mediterranean diet (combined with physical activity and lifestyle counseling) or a usual-care control group. Mean 1-year weight loss from a subsample of participants was $3.2 \mathrm{~kg}(-3.7 \%)$ in the intervention group versus $0.7 \mathrm{~kg}(-0.8 \%)$ in control participants $(95 \% \mathrm{CI}=-3.1$, -1.9) (118). (The trial's primary outcome is a composite score for cardiovascular disease events and has not yet been published.)
Mechanisms. Mechanisms associated with the effects of the Mediterranean diet, as a whole, have not been well investigated. The Mediterranean diet does not put a particular emphasis on macronutrients, an approach that may be helpful for individuals desiring flexibility. Individual components of the Mediterranean diet, such as nuts, have positive effects on decreasing hunger (119). However, it is important to monitor portion sizes, as many of the foods recommended in the Mediterranean diet, such as extra-virgin olive oil, are energy dense. Some patients may have difficulty accessing these foods owing to lack of availability and cost, which could limit adherence. The Mediterranean diet has a host of health benefits other than weight loss, including preventing cardiovascular disease events, which may make it advantageous for many individuals (110).

\section{Factors to consider in selecting a diet}

In the short term, calorie restriction, rather than dietary composition, is the central determinant of weight loss. The most effective diet for initial weight loss is one that someone can adhere to, although such adherence may be discoverable only by a trial of the regimen. Beyond the use of portion-controlled diets and provision of behavioral weight loss counseling, robust factors that facilitate adherence to a diet, on a short- or long-term basis, have yet to be identified.

Several investigators have begun to study diet prescriptions based on factors that include possible gene-diet interactions and baseline insulin levels (120-122). Yet, RCTs that used these factors to potentially promote dietary adherence (and weight loss) largely produced null findings. For example, the DIETFITS trial observed no interaction between weight loss and genotype pattern (low-fat sensitive or low-carbohydrate sensitive) or baseline insulin secretion (72).

Surprisingly, selection of diet based on patient preference, rather than random assignment, has little effect on adherence or weight loss $(123,124)$. In a double-randomized preference trial, participants were randomized to a choice between an LCD or LFD versus random assignment to a diet. At 48 weeks, estimated mean weight loss was $5.7 \mathrm{~kg}$ in the choice group, which did not differ significantly from the $6.7 \mathrm{~kg}$ loss in the no-choice comparison group. Dietary adherence as assessed by the percentage of deviation from the macronutrient intake target was similar between groups. Thus, while having a choice of diets does not appear to enhance weight loss, dieters nonetheless may be more satisfied when trying to lose weight by following a plan they like. Taken together, these studies underscore the critical need to explore factors that drive dietary adherence and weight loss, such as individual variability in physiological responses to different diets.

In addition to inquiring about which weight loss approaches a patient might wish to consider, health professionals also should assess the benefits of different dietary approaches in managing a patient's obesity-related comorbidities. For patients with type 2 diabetes, for example, LCDs appear to produce greater improvements in hemoglobin $A_{1 c}$ and reductions in diabetes medications than LFDs (with higher carbohydrates), despite comparable weight losses with the two approaches $(125,126)$. For patients with hypertension, a DASH-type diet could confer better blood pressure control than an LFD (127). 


\section{Conclusion}

There is not a one-size-fits-all diet for obesity treatment. Adherence to a diet to produce an energy deficit to lose weight and then maintain the loss, regardless of which diet is chosen, is one of the most important factors for obesity treatment. Numerous dietary approaches, with varying calorie levels and macronutrient compositions, produce clinically meaningful weight loss in the short term, with weight regain common to all approaches over time. We observed wide variability in weight losses and adherence between participants who received the same dietary intervention in the same trial, as well as among trials conducted at different sites. There is not convincing evidence that one diet is universally easier to adhere to than another for extended periods, a feature necessary for long-term weight management. Progress in improving dietary adherence could result from greater efforts to examine mechanisms underlying interindividual variability in responses to dietary approaches.
Identifying behavioral and metabolic phenotypes among dieters based on characteristics such as habitual hunger and satiation, as illustrated in Figure 1, could be used to improve the precision of dietary recommendations for obesity treatment to optimize adherence and subsequent weight loss. The more we understand the characteristics of individuals who are trying to lose weight, the more able we may be to identify dietary interventions that facilitate their efforts.

\section{Acknowledgments}

AMC was supported, in part, by the National Institute of Nursing Research of the NIH under Award K23NR017209.

Address correspondence to: Ariana M. Chao, University of Pennsylvania School of Nursing, 3535 Market Street, Suite 3108, Philadelphia, Pennsylvania 19104, USA. Phone: 215.746.7183; Email: arichao@nursing.upenn.edu.
1. Platte P, Pirke KM, Wade SE, Trimborn P, Fichter MM. Physical activity, total energy expenditure, and food intake in grossly obese and normal weight women. Int J Eat Disord. 1995;17(1):51-57.

2. Lichtman SW, et al. Discrepancy between self-reported and actual caloric intake and exercise in obese subjects. $N$ Engl J Med. 1992;327(27):1893-1898.

3. Hedrick VE, Dietrich AM, Estabrooks PA, Savla J, Serrano E, Davy BM. Dietary biomarkers: advances, limitations and future directions. Nutr J. 2012;11:109.

4. Sanghvi A, Redman LM, Martin CK, Ravussin E, Hall KD. Validation of an inexpensive and accurate mathematical method to measure long-term changes in free-living energy intake. Am JClin Nutr. 2015;102(2):353-358.

5. Guo J, Robinson JL, Gardner CD, Hall KD. Objective versus self-reported energy intake changes during low-carbohydrate and low-fat diets. Obesity (Silver Spring). 2019;27(3):420-426.

6. Dansinger ML, Gleason JA, Griffith JL, Selker HP, Schaefer EJ. Comparison of the Atkins, Ornish, Weight Watchers, and Zone diets for weight loss and heart disease risk reduction: a randomized trial. JAMA. 2005;293(1):43-53.

7. Alhassan S, Kim S, Bersamin A, King AC, Gardner $\mathrm{CD}$. Dietary adherence and weight loss success among overweight women: results from the A TO Z weight loss study. Int JObes (Lond). 2008;32(6):985-991.

8. Williamson DA, et al. Early behavioral adherence predicts short and long-term weight loss in the POUNDS LOST study. J Behav Med. 2010;33(4):305-314.

9. Acharya SD, et al. Adherence to a behavioral weight loss treatment program enhances weight loss and improvements in biomarkers. Patient Prefer Adherence. 2009;3:151-160.

10. Wadden TA, et al. Four-year weight losses in the Look AHEAD study: factors associated with long-term success. Obesity (Silver Spring). 2011;19(10):1987-1998.

11. Blundell JE, Rogers PJ, Hill AJ. Evaluating the satiating power of foods: implications for acceptance and consumption. In: Solms J, Booth DA, Pang- bourne RM, Raunhardt O, eds. Food Acceptance and Nutrition. Academic Press; 1987:205-219.

12. Blundell J, et al. Appetite control: methodological aspects of the evaluation of foods. Obes Rev. 2010;11(3):251-270.

13. Halford JC, Harrold JA. Satiety-enhancing products for appetite control: science and regulation of functional foods for weight management. Proc Nutr Soc. 2012;71(2):350-362.

14. Hopkins M, Blundell J, Halford J, King N, Finlayson $\mathrm{G}$. The regulation of food intake in humans. In: Feingold KR, et al., eds. Endotext [Internet]. MDText.com Inc.; 2000-2016.

15. Mela DJ. Eating for pleasure or just wanting to eat? Reconsidering sensory hedonic responses as a driver of obesity. Appetite. 2006;47(1):10-17.

16. Kardas P, Lewek P, Matyjaszczyk M. Determinants of patient adherence: a review of systematic reviews. Front Pharmacol. 2013;4:91.

17. Wadden TA, Webb VL, Moran CH, Bailer BA. Lifestyle modification for obesity: new developments in diet, physical activity, and behavior therapy. Circulation. 2012;125(9):1157-1170.

18. Teixeira PJ, et al. Successful behavior change in obesity interventions in adults: a systematic review of self-regulation mediators. BMC Med. 2015;13:84.

19. Peterson ND, Middleton KR, Nackers LM, Medina KE, Milsom VA, Perri MG. Dietary self-monitoring and long-term success with weight management. Obesity. 2014;22(9):1962-1967.

20. Wing RR, Phelan S. Long-term weight loss maintenance. Am J Clin Nutr. 2005;82(1):222S-225S.

21. Burke LE, Wang J, Sevick MA. Self-monitoring in weight loss: a systematic review of the literature. JAm Diet Assoc. 2011;111(1):92-102.

22. Michie S, Abraham C, Whittington C, McAteer J, Gupta S. Effective techniques in healthy eating and physical activity interventions: a metaregression. Health Psychol. 2009;28(6):690-701.

23. Hall KD, Guo J. Obesity energetics: body weight regulation and the effects of diet composition. Gastroenterology. 2017;152(7):1718-1727.e3.

24. Jensen MD, et al. 2013 AHA/ACC/TOS guideline for the management of overweight and obesity in adults: a report of the American College of Car-
diology/American Heart Association Task Force on Practice Guidelines and The Obesity Society. Obesity. 2014;22(S2):S41-S410.

25. Lin PH, et al. Estimation of energy requirements in a controlled feeding trial. Am J Clin Nutr. 2003;77(3):639-645.

26. European Commission. Nutrition. EU website. https://ec.europa.eu/jrc/en/health-knowledge-gateway/promotion-prevention/nutrition. Updated 1/31/20. Accessed October 2, 2020.

27. Office of Disease Prevention Health Promotion. Dietary guidelines for Americans 2015-2020. Skyhorse Publishing Inc.; 2017.

28. Tsai AG, Wadden TA. The evolution of very-low-calorie diets: an update and meta-analysis. Obesity (Silver Spring). 2006;14(8):1283-1293.

29. Van Itallie TB, Yang MU. Cardiac dysfunction in obese dieters: a potentially lethal complication of rapid, massive weight loss. Am JClin Nutr. 1984;39(5):695-702.

30. Wadden TA, Van Itallie TB, Blackburn GL. Responsible and irresponsible use of very-low-calorie diets in the treatment of obesity. JAMA. 1990;263(1):83-85.

31. Mustajoki P, Pekkarinen T. Very low energy diets in the treatment of obesity. Obes Rev. 2001;2(1):61-72.

32. Del Corral P, Chandler-Laney PC, Casazza K, Gower BA, Hunter GR. Effect of dietary adherence with or without exercise on weight loss: a mechanistic approach to a global problem. J Clin Endocrinol Metab. 2009;94(5):1602-1607.

33. Parretti H, et al. Clinical effectiveness of very-low-energy diets in the management of weight loss: a systematic review and meta-analysis of randomized controlled trials. Obes Rev. 2016;17(3):225-234.

34. Heymsfield SB, van Mierlo CA, van der Knaap HC, Heo M, Frier HI. Weight management using a meal replacement strategy: meta and pooling analysis from six studies. Int JObes Relat Metab Disord. 2003;27(5):537-549.

35. Noronha JC, et al. The effect of liquid meal replacements on cardiometabolic risk factors in overweight/obese individuals with type 2 diabetes: a systematic review and meta-analysis 
of randomized controlled trials. Diabetes Care. 2019;42(5):767-776.

36. World Health Organization. Obesity: preventing managing the global epidemic. WHO website. https://www.who.int/nutrition/publications/ obesity/WHO_TRS_894/en/. Accessed October 2, 2020.

37. Jeffery RW, et al. Strengthening behavioral interventions for weight loss: a randomized trial of food provision and monetary incentives. JConsult Clin Psychol. 1993;61(6):1038-1045.

38. Wadden TA, Butryn ML, Byrne KJ. Efficacy of lifestyle modification for long-term weight control. Obes Res. 2004;12(suppl):151S-162S.

39. Wing RR, Jeffery RW. Food provision as a strategy to promote weight loss. Obes Res. 2001;9(suppl 4):271S-275S.

40. Rolls BJ, Rolls ET, Rowe EA, Sweeney K. Sensory specific satiety in man. Physiol Behav. 1981;27(1):137-142.

41. Unick JL, et al. Evaluation of early weight loss thresholds for identifying nonresponders to an intensive lifestyle intervention. Obesity (Silver Spring). 2014;22(7):1608-1616.

42. Look AHEAD Research Group, et al. Association of the magnitude of weight loss and physical fitness change on long-term CVD outcomes: the look AHEAD study. Lancet Diabetes Endocrinol. 2016;4(11):913-921.

43. Lean ME, et al. Primary care-led weight management for remission of type 2 diabetes (DiRECT): an open-label, cluster-randomised trial. Lancet. 2018;391(10120):541-551.

44. Lean MEJ, et al. Durability of a primary care-led weight-management intervention for remission of type 2 diabetes: 2-year results of the DiRECT open-label, cluster-randomised trial. Lancet Diabetes Endocrinol. 2019;7(5):344-355.

45. Headland M, Clifton PM, Carter S, Keogh JB. Weight-loss outcomes: a systematic review and meta-analysis of intermittent energy restriction trials lasting a minimum of 6 months. Nutrients. 2016;8(6):E354.

46. Trepanowski JF, et al. Effect of alternate-day fasting on weight loss, weight maintenance, and cardioprotection among metabolically healthy obese adults: a randomized clinical trial. JAMA Intern Med. 2017;177(7):930-938.

47. Bray GA, Wadden TA. Improving long-term weight loss maintenance: Can we do it? Obesity (Silver Spring). 2015;23(1):2-3.

48. Harvie M, et al. The effect of intermittent energy and carbohydrate restriction v. daily energy restriction on weight loss and metabolic disease risk markers in overweight women. Br J Nutr. 2013;110(8):1534-1547.

49. Beaulieu K, et al. Matched weight loss through intermittent or continuous energy restriction does not lead to compensatory increases in appetite and eating behavior in a randomized controlled trial in women with overweight and obesity. J Nutr. 2020;150(3):623-633.

50. Sundfør TM, Svendsen M, Tonstad S. Effect of intermittent versus continuous energy restriction on weight loss, maintenance and cardiometabolic risk: a randomized 1-year trial. Nutr Metab Cardiovasc Dis. 2018;28(7):698-706.

51. Harvie M, Howell A. Potential benefits and harms of intermittent energy restriction and intermittent fasting amongst obese, overweight and normal weight subjects - a narrative review of human and animal evidence. Behav Sci (Basel). 2017;7(1):4.

52. Ryan DH, et al. Look AHEAD (Action for Health in Diabetes): design and methods for a clinical trial of weight loss for the prevention of cardiovascular disease in type 2 diabetes. Control Clin Trials. 2003;24(5):610-628.

53. Diabetes Prevention Program Research Group. The Diabetes Prevention Program (DPP): description of lifestyle intervention. Diabetes Care. 2002;25(12):2165-2171.

54. Knowler WC, et al. Reduction in the incidence of type 2 diabetes with lifestyle intervention or metformin. N Engl J Med. 2002;346(6):393-403.

55. West DS, Elaine Prewitt T, Bursac Z, Felix HC. Weight loss of black, white, and Hispanic men and women in the Diabetes Prevention Program. Obesity (Silver Spring). 2008;16(6):1413-1420.

56. Jaacks L, et al. Long-term changes in dietary and food intake behaviour in the Diabetes Prevention Program Outcomes Study. Diabet Med. 2014;31(12):1631-1642.

57. Astrup A, Grunwald GK, Melanson EL, Saris WH, Hill JO. The role of low-fat diets in body weight control: a meta-analysis of ad libitum dietary intervention studies. Int JObes Relat Metab Disord. 2000;24(12):1545-1552.

58. Astrup A. The role of dietary fat in the prevention and treatment of obesity. Efficacy and safety of low-fat diets. Int JObes Relat Metab Disord. 2001;25(suppl 1):S46-S50.

59. Blundell JE, Burley VJ, Cotton JR, Lawton CL. Dietary fat and the control of energy intake: evaluating the effects of fat on meal size and postmeal satiety. Am J Clin Nutr. 1993;57(5 suppl):772S-777S.

60. Stubbs RJ, Harbron CG, Murgatroyd PR, Prentice AM. Covert manipulation of dietary fat and energy density: effect on substrate flux and food intake in men eating ad libitum. Am JClin Nutr. 1995;62(2):316-329.

61. Rolls BJ. Dietary energy density: applying behavioural science to weight management. Nutr Bull. 2017;42(3):246-253.

62. Meyer-Gerspach AC, et al. Gastric and intestinal satiation in obese and normal weight healthy people. Physiol Behav. 2014;129:265-71.

63. Stubbs RJ, Harbron CG, Prentice AM. Covert manipulation of the dietary fat to carbohydrate ratio of isoenergetically dense diets: effect on food intake in feeding men ad libitum. Int JObes Relat Metab Disord. 1996;20(7):651-660.

64. Rolls BJ, et al. Volume of food consumed affects satiety in men. Am J Clin Nutr. 1998;67(6):1170-1177.

65. Blundell JE, MacDiarmid JI. Fat as a risk factor for overconsumption: satiation, satiety, and patterns of eating. JAm Diet Assoc. 1997;97(7 suppl):S63-S69.

66. Churuangsuk C, Kherouf M, Combet E, Lean M. Low-carbohydrate diets for overweight and obesity: a systematic review of the systematic reviews. Obes Rev. 2018;19(12):1700-1718.

67. Nordmann AJ, et al. Effects of low-carbohydrate vs low-fat diets on weight loss and cardiovascular risk factors: a meta-analysis of randomized controlled trials. Arch Intern Med. 2006;166(3):285-293.

68. Hession M, Rolland C, Kulkarni U, Wise A, Broom J. Systematic review of randomized controlled trials of low-carbohydrate vs. low-fat/low-calorie diets in the management of obesity and its comorbidities. Obes Rev. 2009;10(1):36-50.

69. Sackner-Bernstein J, Kanter D, Kaul S. Dietary intervention for overweight and obese adults: comparison of low-carbohydrate and low-fat diets. a meta-analysis. PLoS One. 2015;10(10):e0139817.

70. Mansoor N, Vinknes KJ, Veierød MB, Retterstøl K. Effects of low-carbohydrate diets v. low-fat diets on body weight and cardiovascular risk factors: a meta-analysis of randomised controlled trials. Br J Nutr. 2016;115(3):466-479.

71. Foster GD, et al. A randomized trial of a low-carbohydrate diet for obesity. $\mathrm{N} \mathrm{EnglJ} \mathrm{Med.}$ 2003;348(21):2082-2090.

72. Gardner CD, et al. Effect of low-fat vs low-carbohydrate diet on 12-month weight loss in overweight adults and the association with genotype pattern or insulin secretion: the DIETFITS randomized clinical trial. JAMA. 2018;319(7):667-679.

73. Naude CE, Schoonees A, Senekal M, Young T, Garner P, Volmink J. Low carbohydrate versus isoenergetic balanced diets for reducing weight and cardiovascular risk: a systematic review and meta-analysis. PLoS ONE. 2014;9(7):e100652.

74. VanItallie TB, Nufert TH. Ketones: metabolism's ugly duckling. Nutr Rev. 2003;61(10):327-341.

75. Feinman RD, et al. Dietary carbohydrate restriction as the first approach in diabetes management: critical review and evidence base. Nutrition. 2015;31(1):1-13.

76. Castellana M, et al. Efficacy and safety of very low calorie ketogenic diet (VLCKD) in patients with overweight and obesity: a systematic review and meta-analysis. Rev Endocr Metab Disord. 2019;(1):1-12

77. Bueno NB, de Melo IS, de Oliveira SL, da Rocha Ataide T. Very-low-carbohydrate ketogenic diet v. low-fat diet for long-term weight loss: a meta-analysis of randomised controlled trials. $\mathrm{Br}$ JNutr. 2013;110(7):1178-1187.

78. Jenkins DJ, et al. Glycemic index of foods: a physiological basis for carbohydrate exchange. Am J Clin Nutr. 1981;34(3):362-366.

79. Zafar M, et al. Low glycaemic index diets as an intervention for obesity: a systematic review and meta-analysis. Obes Rev. 2019;20(2):290-315.

80. Schwingshackl L, Hoffmann G. Long-term effects of low glycemic index/load vs. high glycemic index/load diets on parameters of obesity and obesity-associated risks: a systematic review and meta-analysis. Nutr Metab Cardiovasc Dis. 2013;23(8):699-706.

81. Zafar MI, et al. Low-glycemic index diets as an intervention for diabetes: a systematic review and meta-analysis. Am J Clin Nutr. 2019;110(4):891-902.

82. Ludwig DS, Ebbeling CB. The carbohydrate-insulin model of obesity: beyond "calories in, calories out”. JAMA Intern Med. 2018;178(8):1098-1103.

83. Jenkins DJ, et al. Metabolic effects of a low-glycemic-index diet. Am J Clin Nutr. 1987;46(6):968-975.

84. Ludwig DS. The glycemic index: physiolog- 
ical mechanisms relating to obesity, diabetes, and cardiovascular disease. JAMA. 2002;287(18):2414-2423.

85. Hall K. A review of the carbohydrate-insulin model of obesity. Eur JClin Nutr. 2017;71(3):323-326.

86. Sumithran P, et al. Ketosis and appetite-mediating nutrients and hormones after weight loss. Eur JClin Nutr. 2013;67(7):759-764.

87. Lean M, Malkova D. Altered gut and adipose tissue hormones in overweight and obese individuals: cause or consequence? Int JObes (Lond). 2016;40(4):622-632.

88. Gibbons C, et al. Comparison of postprandial profiles of ghrelin, active GLP-1, and total PYY to meals varying in fat and carbohydrate and their association with hunger and the phases of satiety. JClin Endocrinol Metab. 2013;98(5):E847-E855.

89. Hall KD, et al. A plant-based, low-fat diet decreases ad libitum energy intake compared to an animal-based, ketogenic diet: an inpatient randomized controlled trial. https://doi. org/10.31232/osf.io/rdjfb.

90. Martin CK, et al. Change in food cravings, food preferences, and appetite during a low-carbohydrate and low-fat diet. Obesity (Silver Spring). 2011;19(10):1963-1970.

91. Gibson AA, et al. Do ketogenic diets really suppress appetite? A systematic review and meta-analysis. Obes Rev. 2015;16(1):64-76.

92. Johnstone AM, Horgan GW, Murison SD, Bremner DM, Lobley GE. Effects of a high-protein ketogenic diet on hunger, appetite, and weight loss in obese men feeding ad libitum. Am J Clin Nutr. 2008;87(1):44-55.

93. Adam-Perrot A, Clifton P, Brouns F. Low-carbohydrate diets: nutritional and physiological aspects. Obes Rev. 2006;7(1):49-58.

94. Yancy WS, Olsen MK, Guyton JR, Bakst RP, Westman EC. A low-carbohydrate, ketogenic diet versus a low-fat diet to treat obesity and hyperlipidemia: a randomized, controlled trial. Ann Intern Med. 2004;140(10):769-777.

95. Wycherley TP, Moran LJ, Clifton PM, Noakes M, Brinkworth GD. Effects of energy-restricted high-protein, low-fat compared with standard-protein, low-fat diets: a meta-analysis of randomized controlled trials. Am J Clin Nutr. 2012;96(6):1281-1298.

96. Schwingshackl L, Hoffmann G. Long-term effects of low-fat diets either low or high in protein on cardiovascular and metabolic risk factors: a systematic review and meta-analysis. Nutr J. 2013;12:48.

97. Larsen TM, et al. Diets with high or low protein content and glycemic index for weight-loss maintenance. $N$ Engl J Med. 2010;363(22):2102-2113.

98. Aller $\mathrm{E}$, et al. Weight loss maintenance in overweight subjects on ad libitum diets with high or low protein content and glycemic index: the DIOGENES trial 12-month results. Int JObes (Lond). 2014;38(12):1511-1517.

99. Clifton PM, Keogh JB, Noakes M. Long-term effects of a high-protein weight-loss diet. Am J Clin Nutr. 2008;87(1):23-29.
100.Astrup A. The satiating power of protein - a key to obesity prevention? Am JClin Nutr. 2005;82(1):1-2

101.Paddon-Jones D, Westman E, Mattes RD, Wolfe RR, Astrup A, Westerterp-Plantenga M. Protein, weight management, and satiety. Am JClin Nutr. 2008;87(5):1558S-1561S.

102. Tannous dit El Khoury D, Obeid O, Azar ST, Hwalla N. Variations in postprandial ghrelin status following ingestion of high-carbohydrate, high-fat, and high-protein meals in males. Ann Nutr Metab. 2006;50(3):260-269.

103. Soenen S, Martens EA, Hochstenbach-Waelen A, Lemmens SG, Westerterp-Plantenga MS. Normal protein intake is required for body weight loss and weight maintenance, and elevated protein intake for additional preservation of resting energy expenditure and fat free mass. J Nutr. 2013;143(5):591-596.

104.Westerterp-Plantenga MS, Lejeune MP, Nijs I, van Ooijen M, Kovacs EM. High protein intake sustains weight maintenance after body weight loss in humans. Int JObes Relat Metab Disord. 2004;28(1):57-64.

105. Drummen M, et al. High compared with moderate protein intake reduces adaptive thermogenesis and induces a negative energy balance during long-term weight-loss maintenance in participants with prediabetes in the postobese state: a PREVIEW study. J Nutr. 2020;150(3):458-463.

106. Sacks FM, et al. Comparison of weight-loss diets with different compositions of fat, protein, and carbohydrates. NEnglJMed.2009;360(9):859-873.

107. Dietary Guidelines Advisory Committee. Scientific Report of the 2020 Dietary Guidelines Advisory Committee: Advisory Report to the Secretary of Agriculture and the Secretary of Health and Human Services. U.S. Department of Agriculture, Agricultural Research Service, Washington, DC, USA;2020.

108. Soltani S, Shirani F, Chitsazi MJ, Salehi-Abargouei A. The effect of dietary approaches to stop hypertension (DASH) diet on weight and body composition in adults: a systematic review and meta-analysis of randomized controlled clinical trials. Obes Rev. 2016;17(5):442-454.

109. Esposito K, Kastorini CM, Panagiotakos DB, Giugliano D. Mediterranean diet and weight loss: meta-analysis of randomized controlled trials. Metab Syndr Relat Disord. 2011;9(1):1-12.

110.Estruch R, et al. Primary prevention of cardiovascular disease with a Mediterranean diet supplemented with extra-virgin olive oil or nuts. $N$ Engl J Med. 2018;378(25):e34.

111. Bach-Faig A, et al. Mediterranean diet pyramid today. Science and cultural updates. Public Health Nutr. 2011;14(12A):2274-2284.

112. Davis C, Bryan J, Hodgson J, Murphy K. Definition of the Mediterranean diet; a literature review. Nutrients. 2015;7(11):9139-9153.

113. Zaragoza-Martí A, Cabañero-Martínez MJ, Hurtado-Sánchez JA, Laguna-Pérez A, Ferrer-Cascales R. Evaluation of Mediterranean diet adherence scores: a systematic review. BMJ Open. 2018;8(2):e019033.

114. Hernández-Ruiz A, García-Villanova B, Guerra Hernández EJ, Amiano P, Azpiri M, Molina-Mon- tes E. Description of indexes based on the adherence to the Mediterranean dietary pattern: a review. Nutr Hosp. 2015;32(5):1872-1884.

115. Nordmann AJ, et al. Meta-analysis comparing Mediterranean to low-fat diets for modification of cardiovascular risk factors. Am J Med 2011;124(9):841-851.e2.

116. Shai I, et al. Weight loss with a low-carbohydrate, Mediterranean, or low-fat diet. $N$ Engl J Med. 2008;359(3):229-241.

117. Greenberg I, Stampfer MJ, Schwarzfuchs D, Shai I, DIRECT Group. Adherence and success in long-term weight loss diets: the dietary intervention randomized controlled trial (DIRECT). JAm Coll Nutr. 2009;28(2):159-168.

118. Salas-Salvadó J, et al. Effect of a lifestyle intervention program with energy-restricted mediterranean diet and exercise on weight loss and cardiovascular risk factors: one-year results of the PREDIMED-plus trial. Diabetes Care. 2019;42(5):777-788.

119. Akhlaghi M, Ghobadi S, Zare M, Foshati S. Effect of nuts on energy intake, hunger, and fullness, a systematic review and meta-analysis of randomized clinical trials. Crit Rev Food Sci Nutr. 2020;60(1):84-93.

120. Qi Q, Bray GA, Smith SR, Hu FB, Sacks FM, Q L. Insulin receptor substrate 1 gene variation modifies insulin resistance response to weightloss diets in a 2-year randomized trial: the Preventing Overweight Using Novel Dietary Strategies (POUNDS LOST) trial. Circulation. 2011;124(5):563-571.

121. Ebbeling CB, Leidig MM, Feldman HA, Lovesky MM, Ludwig DS. Effects of a low-glycemic load vs low-fat diet in obese young adults: a randomized trial. JAMA. 2007;297(19):2092-2102.

122. McClain AD, Otten JJ, Hekler EB, Gardner $\mathrm{CD}$. Adherence to a low-fat vs. low-carbohydrate diet differs by insulin resistance status. 2013;15(1):87-90.

123. Yancy WS, et al. Effect of allowing choice of diet on weight loss: a randomized trial. Ann Intern Med.2015;162(12):805-814.

124. Burke LE, et al. Effects of a vegetarian diet and treatment preference on biochemical and dietary variables in overweight and obese adults: a randomized clinical trial. Am JClin Nutr. 2007;86(3):588-596.

125. Mayer SB, Jeffreys AS, Olsen MK, McDuffie JR, Feinglos MN, Yancy WS. Two diets with different haemoglobin A1c and antiglycaemic medication effects despite similar weight loss in type 2 diabetes. Diabetes Obes Metab. 2014;16(1):90-93.

126. Tay J, et al. Effects of an energy-restricted low-carbohydrate, high unsaturated fat/low saturated fat diet versus a high-carbohydrate, low-fat diet in type 2 diabetes: a 2-year randomized clinical trial. Diabetes Obes Metab. 2018;20(4):858-871.

127. Siervo M, Lara J, Chowdhury S, Ashor A, Oggioni C, Mathers JC. Effects of the Dietary Approach to Stop Hypertension (DASH) diet on cardiovascular risk factors: a systematic review and meta-analysis. Br J Nutr. 2015;113(1):1-15. 